\title{
Hypercholesterolemia and microvascular dysfunction: interventional strategies
}

\author{
Phoebe A Stapleton ${ }^{1,2}$, Adam G Goodwill ${ }^{1,3}$, Milinda E James ${ }^{1,3}$, Robert W Brock ${ }^{1,3}$, Jefferson C Frisbee ${ }^{1,3^{*}}$
}

\begin{abstract}
Hypercholesterolemia is defined as excessively high plasma cholesterol levels, and is a strong risk factor for many negative cardiovascular events. Total cholesterol levels above $200 \mathrm{mg} / \mathrm{dl}$ have repeatedly been correlated as an independent risk factor for development of peripheral vascular (PVD) and coronary artery disease (CAD), and considerable attention has been directed toward evaluating mechanisms by which hypercholesterolemia may impact vascular outcomes; these include both results of direct cholesterol lowering therapies and alternative interventions for improving vascular function. With specific relevance to the microcirculation, it has been clearly demonstrated that evolution of hypercholesterolemia is associated with endothelial cell dysfunction, a nearcomplete abrogation in vascular nitric oxide bioavailability, elevated oxidant stress, and the creation of a strongly pro-inflammatory condition; symptoms which can culminate in profound impairments/alterations to vascular reactivity. Effective interventional treatments can be challenging as certain genetic risk factors simply cannot be ignored. However, some hypercholesterolemia treatment options that have become widely used, including pharmaceutical therapies which can decrease circulating cholesterol by preventing either its formation in the liver or its absorption in the intestine, also have pleiotropic effects with can directly improve peripheral vascular outcomes. While physical activity is known to decrease PVD/CAD risk factors, including obesity, psychological stress, impaired glycemic control, and hypertension, this will also increase circulating levels of high density lipoprotein and improving both cardiac and vascular function. This review will provide an overview of the mechanistic consequences of the predominant pharmaceutical interventions and chronic exercise to treat hypercholesterolemia through their impacts on chronic sub-acute inflammation, oxidative stress, and microvascular structure/function relationships.
\end{abstract}

\section{Introduction}

While hypercholesterolemia, defined as excessively high plasma cholesterol levels, has emerged as a strong risk factor for cardiovascular disease (CVD). Data acquired by the National Health and Nutrition Examination Survey (NHANES) 2005-2006 found that the mean total serum cholesterol for Americans over the age of 20 was $199 \mathrm{mg} / \mathrm{dl}$, approximating the American Heart Association (AHA) recommended level of $200 \mathrm{mg} / \mathrm{dl}$ [1]. Unfortunately, $16 \%$ of adults were found to have total cholesterol levels of more than $240 \mathrm{mg} / \mathrm{dl}$, a level considered by the AHA to carry twice the CVD risk of those individuals at the desired level $[1,2]$.

Total cholesterol can be broken down into a diagnostic lipoprotein profile, including high density lipoprotein

\footnotetext{
* Correspondence: jfrisbee@hsc.wvu.edu

${ }^{1}$ Center for Cardiovascular and Respiratory Sciences, West Virginia University School of Medicine, 1 Medical Center Drive, Morgantown, WV 26506, USA Full list of author information is available at the end of the article
}

(HDL), low density lipoprotein (LDL), intermediate density lipoproteins (IDL), very low density lipoprotein (VLDL), chylomicron remnants, and triglycerides. With respect to these markers, the AHA publishes recommendations summarized in Table 1 [1]. HDL is considered to be beneficial as higher levels have been correlated with reduced risk of negative cardiovascular events, in large measure by promoting reverse cholesterol transport, an anti-atherogenic process resulting in cholesterol from peripheral tissues returning to the liver for subsequent processing [1]. Elevated LDL cholesterol and triglycerides are considered detrimental as their increased concentration is well correlated with poor cardiovascular outcomes $[1,3]$. Ongoing study has also suggested that IDL, VLDL, and chylomicron remnants may also play an active role in peripheral vascular (PVD) and coronary artery disease (CAD) development [3].

As high total cholesterol levels are considered to be a major independent risk factor for development of PVD 
Table 1 American Heart Association guidelines for cholesterol and triglycerides levels in adults. Last updated 7/2/09

\begin{tabular}{ccccc}
\hline & Total & LDL & HDL & Triglycerides \\
\hline Optimal & - & $<100 \mathrm{mg} / \mathrm{dL}$ & $>60 \mathrm{mg} / \mathrm{dL}$ & - \\
\hline Near optimal/above optimal & $<200 \mathrm{mg} / \mathrm{dL}$ & $100-129 \mathrm{mg} / \mathrm{dL}$ & $\begin{array}{c}40-50 \mathrm{mg} / \mathrm{dL} \text { (men) } \\
50-60 \mathrm{mg} / \mathrm{dL} \text { (women) }\end{array}$ & $<150 \mathrm{mg} / \mathrm{dL}$ \\
\hline Borderline high & $200-239 \mathrm{mg} / \mathrm{dL}$ & $130-159 \mathrm{mg} / \mathrm{dL}$ & - & $150-199 \mathrm{mg} / \mathrm{dL}$ \\
\hline High & - & $160-189 \mathrm{mg} / \mathrm{dL}$ & $<00-499 \mathrm{mg} / \mathrm{dL}$ \\
\hline Very high & $\geq 240 \mathrm{mg} / \mathrm{dL}$ & $>190 \mathrm{mg} / \mathrm{dL}$ & $<40 \mathrm{mg} / \mathrm{dL}$ (men) & $\geq 500 \mathrm{mg} / \mathrm{dL}$ \\
\hline
\end{tabular}

* If the patient has additional risk factors LDL levels are recommended under $70 \mathrm{mg} / \mathrm{dL}$.

and CAD, considerable attention has been directed toward evaluating the impact and mechanisms of cholesterol lowering therapies and interventions for cardiovascular outcomes [2-4]. Cholesterol has been shown to interrupt and alter vascular structure and function as it builds within the lining of the vascular wall, and can interfere with endothelial function leading to lesions, plaques, occlusion, and emboli; along with a reduction in healing, recovery, and appropriate management of ischemia/reperfusion injury [5-9]. With specific relevance to the microcirculation, it has been clearly demonstrated that evolution of hypercholesterolemia is associated with endothelial cell dysfunction [5,10-14]. Additionally, reports have shown a near-complete abrogation in vascular nitric oxide (NO) bioavailability, elevated oxidant stress, and the creation of a strongly pro-inflammatory condition; symptoms which can culminate in profound impairments to vascular reactivity $[10,12,15-22]$. Investigation into vascular consequences of chronic hypercholesterolemia, the mechanisms through which these consequences occur, and the potentially beneficial effects of ameliorative therapies have received considerable attention in recent years [3,9,12,15,17,23-26].

Although a substantial risk factor for CVD, hypercholesterolemia has also been demonstrated to be manageable, as summarized in meta-analytic projects which have supported the use of pharmaceutical interventions to reduce cholesterol, with the outcome of lowering cardiovascular event incidence [24,27]. However, effective interventional treatment can be problematic, as the presence of specific genetic risk factors are frequently present. The condition of familial hypercholesterolemia $(\mathrm{FH})$ is an inherited autosomal dominant disorder caused by variations to the low density lipoprotein receptor (LDLR) gene, preventing effective function and dramatically elevating levels of circulating LDL [28]. While the phenotypic effects of the homozygous condition are more severe, the prevalence of the heterozygous condition affects approximately 1 in 500 individuals [29]. Normally, LDL transports cholesterols and fats through the aqueous bloodstream to the cell surface where LDLR mediates its endocytosis, a process that is rendered ineffective in $\mathrm{FH}$. A second inherited cause of hypercholesterolemia is familial combined hyperlipidemia $(\mathrm{FCH})$, also known as type III hyperlipidemia, which presents high cholesterol and high triglyceride levels stemming from a number of gene polymorphisms [30]. Interestingly, while the dyslipidemic profile of these two conditions differs, there is a striking similarity in the poor vascular outcomes $[8,12]$.

\section{Hypercholesterolemia and Vascular Dysfunction}

The vascular endothelium, a single cell layer on the inner surface of all vessels, is capable of producing numerous bioactive molecules, thereby acting as an autocrine, paracrine, and endocrine organ [26]. In a normal system, endothelial cells maintain vascular tone via endotheliumderived relaxing factors including NO, prostacyclin, and endothelium-derived hyperpolarizing factors [14] in an integrated balance with sympathetic and myogenic tone as well as parenchymal cell influences. These molecules help to regulate the homeostasis of the vascular system by adjusting to a number of systemic demands on blood flow, coagulation, inflammation, platelet aggregation, and signal transduction, with any decay in efficacy considered as dysfunction [31].

Nitric oxide (NO), a gas synthesized from the amino acid L-arginine through the enzyme nitric oxide synthase (NOS), has been widely considered as an endotheliumdependent regulator of vascular tone, with additional roles in preventing platelet activation, inhibiting oxidative stress, cell growth, and inflammation, among others $[16,32]$. Asymmetric dimethylarginine (ADMA) is an endogenous inhibitor of NOS through competition with L-arginine [22]. Given recent studies demonstrating an increased endogenous production of ADMA in hypercholesterolemia and the inverse relationship between $\mathrm{NO}$ production and ADMA concentration, ADMA elevations are currently under intensive evaluation as an additional risk factor for CVD [20,22].

Previous studies within our laboratory and others have shown that dilator reactivity in response to NO-dependent stimuli is moderately impaired in hypercholesterolemic mice as compared to responses in control animals 
[12,19,33-37]. This reduction is not due to an inability to react to the NO signal, as vessels are able to respond normally to NO donors, rather there is a reduction in the bioavailability of $\mathrm{NO}$ within vasculature either via deficits in production or due to increased oxidant scavenging [13]. Additional data suggests that NOmediated endothelium-dependent responses within a hypercholesterolemic milieu may differ between conduit vessels and the microcirculation, as peripheral resistance arterioles have a greater sensitivity to local metabolite production [38-40]. Further, in hypercholesterolemic mice and diet induced hypercholesterolemic rabbits, compensatory mechanisms evolve to maintain endothelium-dependent dilation as a result of a decrease in $\mathrm{NO}$ bioavailability, and appear to involve altered patterns of arachidonic acid metabolism involving both the cyclooxygenase and lipoxygenase pathways [11,12,23,41-43]. Arachidonic acid action within hypercholesterolemia is not limited to metabolite production inducing dilation, but includes the production of thromboxane $\mathrm{A}_{2}$ ( $\mathrm{TXA}_{2}$ ), a potent vasoconstrictor $[15,44]$. Hypercholesterolemic animals have shown a limitation to arachidonic acid induced dilation due to an increase in $\mathrm{TXA}_{2}$ production during metabolism [15]. Similar hypercholesterolemic animals have shown an improvement in vascular reactivity and atherosclerotic lesions in animals who are thromboxane receptor deficient $[15,45,46]$.

The vascular consequences of lipoprotein remnants within the hypercholesterolemia, independent of but in addition to endothelial dysfunction, can lead to organ dysfunction and subsequently greater systemic consequences due to an impairment of tissue perfusion. This impairment can be classified as arteriolar remodeling or capillary rarefaction due to the buildup of cholesterol within the hyperlipidemic population. Rarefaction may play a role in many of the systemic effects stemming from structural pathologies reported within this population, including but not limited to changes within the skin, glomerulopathy leading toward kidney dysfunction and hypertension, reductions in coronary flow reserve leading to an early coronary heart disease and hepatic dysfunction leading toward non-alcoholic fatty liver disease [47-51].

\section{Hypercholesterolemia and Inflammation}

Numerous studies have clearly established that hypercholesterolemia leads to an inflammatory response within the microvasculature, reflected by endothelial cell activation, leukocyte recruitment, rolling and adherence, as well as platelet activation and adhesion characterized in Figure 1 [18,52]. Platelet activation can initiate leukocyte recruitment to lesion prone areas as evidenced by an increased surface CD40 expression indicative of cellular activation $[18,53]$. Leukocyte activation can subsequently obstruct capillary networks, reducing capillary perfusion - a condition previously identified in hypercholesterolemia [19].

The decreased bioavailability of NO in hypercholesterolemia also diminishes the anti-inflammatory properties of the endothelial cell, permitting the activity of growth factors on the cell surface and platelet activation to act as chemoattractants to a parade of inflammatory events. Leukocytes begin to roll along the lumen and adhere to the cell wall, extravasating due to an increase in vascular permeability, and residing within the intimal space [22]. Monocyte chemotactic protein-1 (MCP-1) and interleukin-8 (IL-8) have both been found to be important in hypercholesterolemic patients, acting to increase monocyte recruitment and adherence which leads to wall remodeling [6,54-56]. Macrophages, derived from monocytes, begin to accumulate LDL and oxidized LDL (oxLDL) which develop into foam cells between the basal lamina of the endothelium and the smooth muscle layer [26]. These foam cells lead to the production of numerous inflammatory and oxidative stress markers, cytokines, chemokines, and growth factors which aggravate the balance of endothelial equilibrium leading to vascular dysfunction [57].

Elevated cholesterol has also been shown to trigger the release of the inflammatory mediator $\mathrm{C}$-reactive protein (CRP), a useful clinical marker of CVD $[58,59]$. It is hypothesized that CRP, via IL-6, may exacerbate vascular dysfunction by inhibiting eNOS, stimulating production of reactive oxygen species and increasing vascular permeability, and may also initiate the expression and stimulation of adhesion molecules, chemokine production, and thrombus formation within endothelial cells [54]. Unfortunately, as a cellular marker of vascular inflammation, the source of CRP within the hypercholesterolemic condition is unclear [60].

\section{Hypercholesterolemia and Oxidative Stress}

Excess oxidative stress is caused by an imbalance between pro- and anti-oxidant enzymes, leading to an overproduction of free radicals, including superoxide, hydroxyl radicals, and lipid radicals, which may damage cellular components, interfering with normal function again characterized in Figure 1. Other molecules such as peroxynitrite, hydrogen peroxide, and hypochlorous acid are also oxidants, but are not free radicals. The two major sources of oxidants within the vasculature are leukocytes (macrophages) recruited due to an endothelial injury signal and inefficiencies within smooth muscle cell mitochondrial metabolism [61].

Hypercholesterolemia may also increase activity of three major oxidant producing enzyme systems; NADPH oxidases (NOX), xanthine oxidase, and myeloperoxidase. NOX acts to transfer an electron to an 


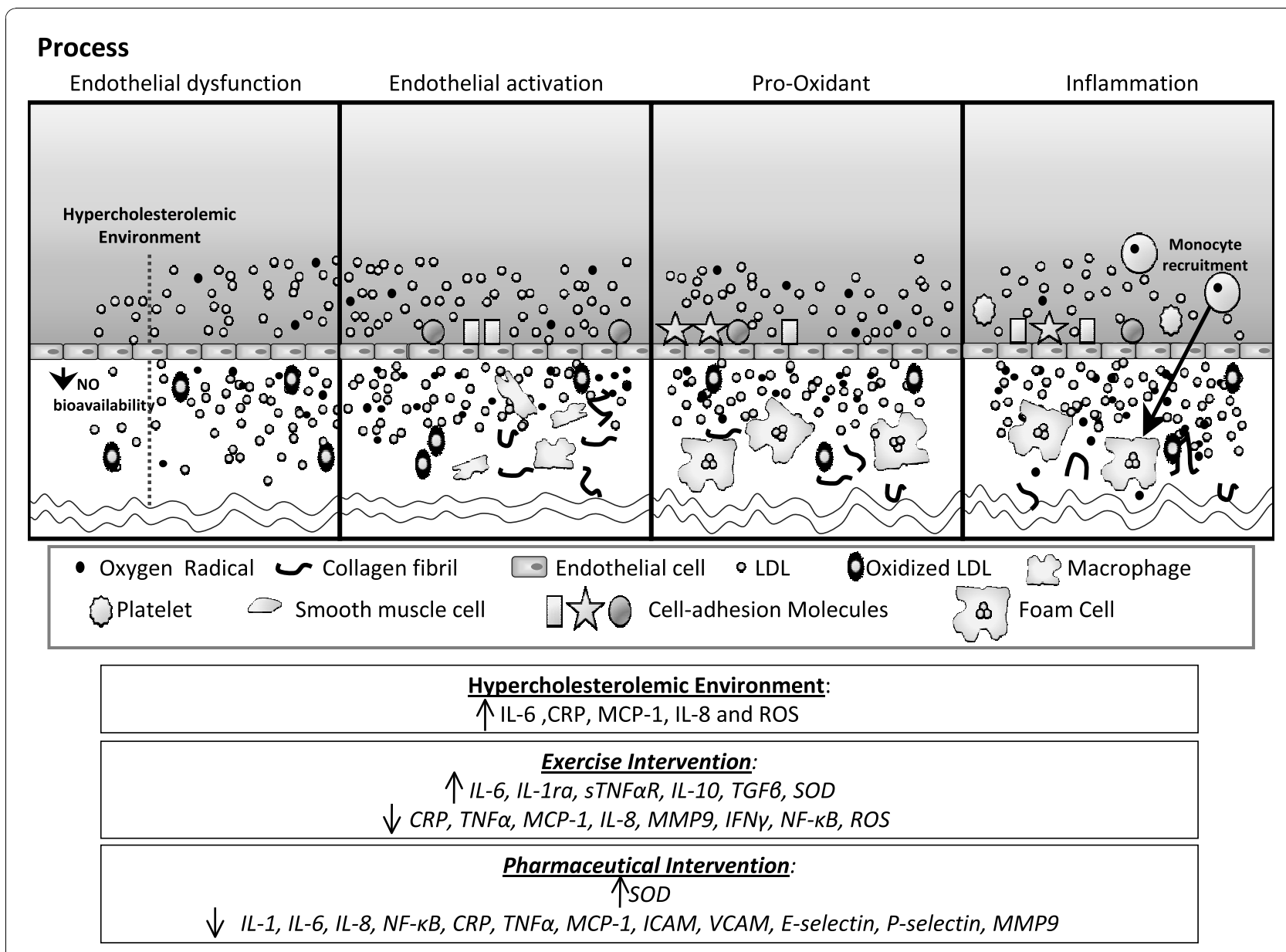

Figure 1 Figure illustrates the vascular progression of disease within a hypercholesterolemic environment. The depiction gives a simplified version of the process, while including documented signaling adaptations associated with hypercholesterolemia, pharmaceutical therapies, and exercise interventions

oxygen molecule, forming superoxide ultimately $\mathrm{H}_{2} \mathrm{O}_{2}$ [62]. While seven NOX isoforms have been identified (NOX1-5, DUOX 1 and 2), four of these (NOX1, 2, 4, and 5) have been recognized within the vascular wall, with NOX2 responsible for the greatest impact on ROSrelated decreases to $\mathrm{NO}$ bioavailability [63]. Xanthine oxidase forms superoxide and $\mathrm{H}_{2} \mathrm{O}_{2}$ during the reduction of oxygen, while myeloperoxidase is produced by neutrophils and monocytes and produces a toxic hypochlorous acid; within a pathological condition overactive enzymes can lead to the overproduction these radicals, leading to scavenging of NO molecules, uncoupling of eNOS, and/or the formation of peroxynitrite [61]. eNOS uncoupling and substrate reduction (tetrahydrobiopterin $\left(\mathrm{BH}_{4}\right)$ and L-arginine), can transform eNOS into a superoxide generating enzyme which can, in turn, produce greater amounts of oxidant radicals and hydrogen peroxide in addition to NO production $[32,64]$.
A range of antioxidant mechanisms are in place to minimize and balance the effects of ROS, including superoxide dismutase (SOD), glutathione peroxidase (GPx4), catalase, and thioredoxin reductase. SOD, which comes in three forms, soluble cytoplasmic (SOD1), extracellular (SOD3) containing copper and zinc and mitochondrial (SOD2) containing manganese, is the main cellular antioxidant system in all cell types and is capable of converting superoxide radicals to $\mathrm{H}_{2} \mathrm{O}_{2}$ and oxygen $[58,65,65]$. GPx4 reduces $\mathrm{H}_{2} \mathrm{O}_{2}$ and lipid peroxides to water and lipid alcohols, and reduces the development of atherosclerosis during hypercholesterolemia through the inhibition of lipid peroxidation and a decreased sensitivity of endothelial cells to oxidized lipids [66]. Catalase acts to reduce hydrogen peroxide to oxygen molecules and water. Within the pathological state of hypercholesterolemia, antioxidant systems are unable to handle the increased demand and the ROS production exceeds capacity. 
Within hypercholesterolemia, reactions between oxygen radicals or enzymatic oxidation and lipoproteins or more specifically phospholipids can lead to production of lipid radicals (oxLDL) or oxidized phospholipids (OxPL). These OxPL can interact with membrane receptors to accumulate within the cellular membrane, disrupting normal cellular function through a reduced bioavailability of NO, eliciting an immune response, leading to poor vascular function, and ultimately atherosclerosis $[14,67,68]$. This conclusion is further supported with evidence that cholesterol fed animals with polyethylene-glycolated-SOD demonstrate an improved endothelium dependent dilation, while normocholesterolemic animals did not show any effects [69]. OxPL can interact directly with the endothelial cell through interactions with the lectin-like oxLDL receptor (LOX-1), an endothelial receptor for oxidized LDL in endothelial cells; this receptor is induced by a variety of inflammatory cytokines, oxidative stress, hemodynamic changes, and abundance of ox-LDL [70]. In addition to oxLDL, LOX-1 can bind advanced glycation end products (AGE), activated platelets, and leukocytes all furthering inflammatory and oxidative processes [70]. Lastly, as the interactions with oxPL cause further injury subsequently activating the endothelial cell and platelets, signaling a variety of adhesion and inflammatory molecules including MCP-1, leading to monocyte recruitment, diapedesis, macrophage differentiation, and foam cell formation only further aggravates the delicate system by producing additional ROS and inflammatory recruitment $[68,71]$.

\section{Hypercholesterolemia and Pharmaceutical Therapies}

Statins, 3-hydroxy-3-methylglutaryl-coenzyme A (HMG CoA) reductase inhibitors, are currently one of the most widely prescribed drugs on the market. They target liver HMG CoA reductase activity and inhibit the production of a cholesterol precursor, mevalonic acid. They also specifically act to change the conformation of HMG-CoA reductase when bound, preventing a functional structure [25]. This enzymatic inhibition acts to prevent protease activation of sterol regulatory element binding proteins (SREBPs) from the endoplasmic reticulum, thereby preventing nuclear translocation and upregulation of LDL gene expression, limiting hepatic cholesterol production [25].

Statins have been identified to have numerous positive outcomes associated with their direct cholesterol lowering [72-75]. However, in addition to these, vasculoprotective properties such as increased NO bioavailability, antioxidant, anti-inflammatory and immunomodulatory properties leading to an overall improvement of endothelial function have also been identified; yet specifically identifying the discrete result in human hypercholesterolemic patients is difficult as the cholesterol lowering benefits are similar [76,77]. Additionally, statin therapy has been found to significantly improve endothelial function (based on flow-mediated dilator responses) in hypercholesterolemic patients who had also been diagnosed with peripheral artery disease [78]. While this beneficial effect may have resulted from an increased NO bioavailability, the underlying mechanisms have not been fully understood [79].

These diverse positive vascular outcomes are most easily identified while using a genetically modified murine model, as the lipid-lowering results become null, leaving the pleiotropic effects evident. While similar to the secondary benefits of direct cholesterol lowering, these independent effects described include: reducing inflammation, decreases in ROS, increases in NO bioavailability and endothelial function, decreases in platelet activation and aggregation, reduction in coagulation and decreases in cellular proliferation, among others [42]. Unfortunately, at this time while the independent outcomes are evident, the mechanisms of action leading to these improvements are not fully elucidated.

Ezetimibe (Zetia) is a selective agent which acts to prevent cholesterol absorption in the intestine through targeting Niemann-Pick C1-like 1 protein (NPC1L1), which is expressed on the intestinal cell surface and is a transporter with secretion signal and sterol-sensing domains. Ezetimibe will inhibit this protein, thereby blocking LDL uptake from the intestine [80]. The subsequent reduction in cholesterol transport to the liver stimulates a compensatory increase in LDLR expression, thereby increasing vascular clearance with no known serious side effects [9]. While cholesterol lowering therapies have shown a positive correlation with reductions in cardiovascular events, ezetimibe has recently begun to show pleiotropic effects such as reductions in liver lipids, reductions in lipid lesions, reductions in ADMA levels, and increases in eNOS mRNA expression [26,75].

When used in combination, ezetimibe and statins (e.g., Vytorin) act via complementary pathways to prevent cholesterol absorption from the intestine and hepatic production. Long term co-administration of these drugs have been shown to reduce LDL blood cholesterol levels by $60 \%$ while concurrently raising HDL levels and limiting liver toxicity, myotoxicity and/or rhabdomyolysis traditionally caused by statin treatment alone $[9,81,82]$. However, at present, the side effects of the combined therapy are not well described, and it is unclear how effective these are for impacting the inflammatory profile $[73,74,83]$.

\section{Oxidant Stress, Inflammation and Pharmaceutical Therapies}

While lowering overall cholesterol levels can lead to a decrease in vascular oxidative stress and thereby improve endothelial function, some groups have found 
antioxidant properties to be a pleiotropic effect of statins [84]. When evaluated to examine NO in a biologically active form, cholesterol lowering drugs were shown to increase the efficiency of the NOS system, while simultaneously showing an inactivation of oxygen radicals within the system [85]. These drugs may not act directly upon the radicals, but instead act to reduce oxidant stress by decreasing substrate availability for these radicals to act upon or by increasing antioxidant enzymatic activities, such as SOD [86]. Statins have found to act upon the p21 Rac protein interrupting the NOX subunit assembly working directly to inhibit the production mechanism of superoxides through disruption of the NOX enzyme [87]. Some studies have shown positive results with respect to lipid peroxidation, including the increase of an antioxidant effect leading to a decrease in ox-LDL with combination ezetimibe/statin treatment [88].

Pharmaceutical treatments have been shown to influence inflammation through the decrease of systemic markers of inflammation and to increase the stability of existing plaques, thereby reducing the risk for thrombosis. Some groups are considering treating LDL as means to managing inflammation and preventing atherosclerotic lesions with mixed reviews and results $[89,90]$.

CRP has been commonly used as a marker of inflammation in a clinical setting since it is associated with low-grade cardiovascular inflammation. Statin drugs have been shown to decrease CRP in numerous human studies, including JUPITER, ENHANCE, CARE, and PRINCE, regardless of their lipid lowering effects [91]. Additional studies have shown an interference with the inflammatory process, impacting the expression of interleukins, adhesion molecules, platelet aggregation, and chemoattractants including IL-1, IL-6, IL-8, NF- $\kappa$ B, and TNF- $\alpha$ culminating in the decrease of CRP [92].

Animal studies have shown atorvastatin to reduce inflammatory markers such as MCP-1 and the activation of the nuclear factor NF- $\kappa \mathrm{B}$ [93]. More recently, as the pleiotropic effects of these interventions are being evaluated, some studies have found reductions in the adhesion molecules ICAM, VCAM, E-selectin, P-selectin, and platelet aggregation. These reductions are leading some to the conclusion that pharmaceutical therapies may reduce or limit the formation and instability of atherosclerotic plaques [94].

\section{Hypercholesterolemia and Exercise}

The AHA and American College of Sports Medicine (ACSM) have recently released joint guidelines recommending aerobic and resistance physical activities for individuals under the age of 65 to maintain health, reduce risk of chronic disease states, and manage current risk factors including hypercholesterolemia [95-97].
Hypercholesterolemia has been shown to impair aerobic capacity by impairing dilator regulation, thought to be due to a lack of vascular reactivity stemming from a reduction in NO bioavailability [98]. However, this decline in vascular reactivity may also be due to wall remodeling as seen in the LDLR mouse model of FH or poor blood flow distribution due to microvessel rarefaction seen in the ApoE mouse model of FCH [56]. These may lead to a decrease in oxygen transport to working skeletal muscles during the hyperemic demand of exercise, further reducing aerobic capacity [98].

Few groups examine dose-response relationships between exercise training and cholesterol adaptations. Some have suggested that exercise can alter blood lipids at low training volumes, although effects may not be significant until certain caloric thresholds are met. Exercise training has rarely been shown to have a direct effect on total cholesterol or LDL levels; however, significant increases in HDL and decreases in triglycerides have been identified [99]. This may be a function of activity intensity, as a $1200-2200 \mathrm{kcal} /$ week exercise program performed at moderate intensities, has been shown to reduce total and LDL cholesterol levels [99].

A number of moderate-intensity exercise programs have shown improvements to systemic aerobic capacity, effectively reversing early stage hypercholesterolemic changes within the vasculature, including improved vascular reactivity, $\mathrm{NO}$ bioavailability and eNOS activity $[40,100]$. These increases in NO bioavailability in humans and animal models of hypercholesterolemia have been attributed to eNOS expression and production of NO, due to a chronic rise in shear stress with exercise, as opposed to an increase in SOD or reduction in oxidant stress [101]. Exercise and shear stress have also been shown to improve mechanisms of endothelial vasodilation other than $\mathrm{NO}$, such as prostaglandin release [12]. Exercise has also been shown to ameliorate increases in inflammatory and oxidative stress markers during chronic disease state, which would benefit many low-grade inflammatory conditions [102].

\section{Inflammation, Oxidant Stress and Exercise}

In the past, inflammation associated with physical activity has been described as the reaction to a number of repeated micro-traumas to the muscle [103]. However, muscle has recently been identified as an endocrine organ, possessing the ability to manufacture and release humoral mediators directly into the system in response to muscle contraction [104]. This establishes a link between skeletal muscle activity and anti-inflammatory effects [105]. The cytokines produced, identified as myokines, include IL-6, IL-8, IL-15, brain-derived neurotrophic factor (BDNF), leukemia inhibitory factor (LIF) FGF21 and follistatin-like-1: each are regulated in some 
manner by the contraction or contractility of muscle [106]. With respect to IL-6, the myokine hypothesis suggests that both type I and type II muscle fibers are capable of producing and releasing IL-6, which may act locally through AMPK signaling or systemically to improve hepatic glucose production and lipid metabolism [107].

During acute exercise, there is an immediate increase in a variety of anti-inflammatory cytokines, such as IL-6, IL-1ra, sTNFR (soluble TNF- $\alpha$ receptor), and IL-10. However, pro-inflammatory cytokines TNF- $\alpha$ (tumor necrosis factor- $\alpha$ ) and IL- 1 are generally not changed [108]. Chronic exercise leads to a reduction of systemic and local markers of inflammation within the vasculature has been well established within the literature [109]. As exercise persists to a chronic state pro-inflammatory markers CRP, TNF- $\alpha$, IFN- $\gamma$, MCP-1, IL-6, IL-8, and MMP-9 have all been shown to decrease from initial baseline levels; whereas anti-inflammatory markers IL-10 and TGF- $\beta$ increase indicating the development of a less inflammatory phenotype $[110,111]$. The timeline and exact mechanisms by which a chronic increase in activity will lead to modest improvements in low-grade inflammation are uncertain [112]. However, some groups are focusing on the "long-term anti-inflammatory effects of exercise" $[105,110]$.

Cellular respiration and metabolism are directly linked to physical activity and exercise as they are the source responsible for muscle action. In the presence of oxygen, aerobic respiration allows for the production of ATP, where glucose is broken down to pyruvate and enters the mitochondria for further processing via Kreb's cycle and oxidation via the electron transport chain. Unfortunately, minor inefficiencies within the mitochondria, including leaky membranes and limited cofactor availability, lead to a reduced ATP generation and the excess buildup of oxidants [113].

In acute exercise alterations to the mitochondrial electron transport chain is a direct source of oxidant stress due to the significant amount of oxidative handling throughout the system [92]. Therefore, any inefficiencies associated within this system are multiplied as mitochondrial requirements increase due to an increase in activity, specifically during acute exercise when there is an increase in whole body oxygen consumption thereby increasing the generation of ROS by active tissues [114]. During the production of these mitochondrial-derived radicals, there is also an increase of the pro-oxidant enzymes xanthine oxidase, myeloperoxidase, and NOX [115]. The upregulation of these enzymes causes an increase in plasma markers of ROS, such as $\mathrm{F}_{2}$-isoprostanes [116]. This increased oxidant stress, while promoting negative cardiovascular effects, has recently been shown to occur in conjunction with increases in antibodies to ox-LDL and antioxidant enzymes (catalase) after one week of activity in mice [117]. These changes suggest that after only a week of moderate activity, there is an initiation to improve hypercholesterolemia, limit the progression of foam cell development, and increase antioxidant enzyme activity within exercising and sedentary states. As exercise persists, mitochondrial and antioxidant enzymes also improve; specifically, an increase in expression of $\mathrm{Cu} / \mathrm{Zn}$ superoxide dismutase (SOD-1) and glutathione peroxidase lead to a higher oxidant handling capacity and contribution to improved function $[101,118]$. As a consequence, there is a decrease in the plasma markers of oxidative stress F2-isoprostane, myeloperoxidase, and malondialdehyde [119]. Exercise training has also been shown to have a direct positive effect on the induction of eNOS and ecSOD (endothelial cell SOD), potent antioxidants. These increases are interdependent, as eNOS ${ }^{-1-}$ mice seem to be unaffected an increase in ecSOD [120].

Exercise and increases in NO have also been shown to induce HO-1 (heme oxygenase-1) expression. HO-1 products have similar anti-oxidant and anti-inflammatory effects, in addition to the inhibition of NF-KB an oxidant stress sensitive transcription factor [121]. The inhibition of NF-kB leads to a decrease of the entire downstream signaling cascade, which could be the link to many of the NO-mediated anti-inflammatory effects observed with chronic exercise such as decreases in leukocyte binding, chemotaxis, aggregation of platelets, and proliferation of smooth muscle cells [122].

\section{Conclusion}

Given the severity of hypercholesterolemia as a risk factor for the progression of negative CVD outcomes, the pathways of effective interventional strategies to manage cholesterol levels, improve vascular reactivity, and restore NO bioavailability warrant continued investment. Pharmaceutical therapies have presented a variety of vasculoprotective effects which are not fully understood, but involve a complex interaction between vascular signaling mechanisms, oxidant stress and chronic inflammation. Additionally, physical activity and exercise have long been suggested as means to modify CVD and manage cholesterol. Current evidence also supports the theory of a long term anti-inflammatory effects through modifications of the IL- 6 and CRP pathways, along with anti-oxidative effects of increased anti-oxidant enzyme expression and activity leading to a higher oxidant handling capacity at rest and during activity. These data suggest that the pleiotropic effects of exercise and conventional pharmaceutical therapies may be most beneficial when used in combination. 


\section{Acknowledgements}

This work was supported by the American Heart Association (EIA 0740129N) and National Institutes of Health (R01 DK64668).

\section{Author details}

${ }^{1}$ Center for Cardiovascular and Respiratory Sciences, West Virginia University School of Medicine, 1 Medical Center Drive, Morgantown, WV 26506, USA.

${ }^{2}$ Division of Exercise Physiology, West Virginia University School of Medicine, 1 Medical Center Drive, Morgantown, WV 26506, USA. ${ }^{3}$ Department of Physiology and Pharmacology, West Virginia University School of Medicine, 1 Medical Center Drive, Morgantown, WV 26506, USA.

\section{Authors' contributions}

PS conceived of the review, performed the literature search, compiled, designed, and drafted the manuscript. AG aided in the literature search and drafted the manuscript. MJ aided the literature search. RB conceived of the review, participated in the design, and execution. JF conceived of the review, participated in the design, and execution. All authors read and approved of the final manuscript.

\section{Competing interests}

The authors declare that they have no competing interests.

Received: 21 May 2010 Accepted: 18 November 2010

Published: 18 November 2010

\section{References}

1. What Do My Cholesterol Levels Mean?. American Heart Association 2007, 6-22-2009

2. Lloyd-Jones D, Adams R, Carnethon M, De SG, Ferguson TB, Flegal K, Ford E, Furie K, Go A, Greenlund K, et al: Heart disease and stroke statistics-2009 update: a report from the American Heart Association Statistics Committee and Stroke Statistics Subcommittee. Circulation 2009, 119:e21-181.

3. Segrest JP: The role of non-LDL:non-HDL particles in atherosclerosis. Curr Diab Rep 2002, 2:282-288

4. Selvin E, Erlinger TP: Prevalence of and risk factors for peripheral arterial disease in the United States: results from the National Health and Nutrition Examination Survey, 1999-2000. Circulation 2004, 110:738-743.

5. Hayakawa H, Raij L: Relationship between hypercholesterolaemia, endothelial dysfunction and hypertension. J Hypertens 1999, 17:611-619.

6. Choudhury RP, Fuster V, Fayad ZA: Molecular, cellular and functional imaging of atherothrombosis. Nat Rev Drug Discov 2004, 3:913-925.

7. Kang J, Albadawi H, Patel VI, Abbruzzese TA, Yoo JH, Austen WG Jr, Watkins MT: Apolipoprotein E-/- mice have delayed skeletal muscle healing after hind limb ischemia-reperfusion. J Vasc Surg 2008, 48:701-708.

8. Stapleton PA, Goodwill AG, James ME, D'Audiffret AC, Frisbee JC. Differential impact of familial hypercholesterolemia and combined hyperlipidemia on vascular wall and network remodeling in mice. Microcirculation 2010, 17:47-58.

9. Huijgen R, Vissers MN, Defesche JC, Lansberg PJ, Kastelein JJ, Hutten BA: Familial hypercholesterolemia: current treatment and advances in management. Expert Rev Cardiovasc Ther 2008, 6:567-581.

10. Boodhwani M, Nakai Y, Mieno S, Voisine P, Bianchi C, Araujo EG, Feng J, Michael K, Li J, Sellke FW: Hypercholesterolemia impairs the myocardial angiogenic response in a swine model of chronic ischemia: role of endostatin and oxidative stress. Ann Thorac Surg 2006, 81:634-641.

11. Drolet MC, Plante E, Battistini B, Couet J, Arsenault M: Early endothelial dysfunction in cholesterol-fed rabbits: a non-invasive in vivo ultrasound study. Cardiovasc Ultrasound 2004, 2:10.

12. Stapleton PA, Goodwill AG, James ME, Frisbee JC: Altered mechanisms of endothelium-dependent dilation in skeletal muscle arterioles with genetic hypercholesterolemia. Am J Physiol Regul Integr Comp Physiol 2007, 293:R1110-R1119.

13. Wolfle SE, de Wit C: Intact endothelium-dependent dilation and conducted responses in resistance vessels of hypercholesterolemic mice in vivo. J Vasc Res 2005, 42:475-482.

14. Jiang F, Gibson AP, Dusting GJ: Endothelial dysfunction induced by oxidized low-density lipoproteins in isolated mouse aorta: a comparison with apolipoprotein-E deficient mice. Eur J Pharmacol 2001, 424:141-149.
15. Goodwill AG, Stapleton PA, James ME, D'Audiffret AC, Frisbee JC: Increased arachidonic acid-induced thromboxane generation impairs skeletal muscle arteriolar dilation with genetic dyslipidemia. Microcirculation 2008, 15:621-631.

16. Kauser K, da C, Fitch R, Mallari C, Rubanyi GM: Role of endogenous nitric oxide in progression of atherosclerosis in apolipoprotein E-deficient mice. Am J Physiol Heart Circ Physiol 2000, 278:H1679-H1685.

17. Pfister SL, Falck JR, Campbell WB: Enhanced synthesis of epoxyeicosatrienoic acids by cholesterol-fed rabbit aorta. Am J Physiol 1991, 261:H843-H852.

18. Stokes KY, Calahan L, Russell JM, Gurwara S, Granger DN: Role of platelets in hypercholesterolemia-induced leukocyte recruitment and arteriolar dysfunction. Microcirculation 2006, 13:377-388.

19. Stokes KY, Cooper D, Tailor A, Granger DN: Hypercholesterolemia promotes inflammation and microvascular dysfunction: role of nitric oxide and superoxide. Free Radic Biol Med 2002, 33:1026-1036.

20. Vladimirova-Kitova L, Deneva T, Angelova E, Nikolov F, Marinov B, Mateva N: Relationship of asymmetric dimethylarginine with flow-mediated dilatation in subjects with newly detected severe hypercholesterolemia. Clin Physiol Funct Imaging 2008, 28:417-425.

21. White CR, Parks DA, Patel RP, Shelton J, Tarpey MM, Freeman BA, rleyUsmar VM: L-Arginine inhibits xanthine oxidase-dependent endothelial dysfunction in hypercholesterolemia. FEBS Lett 2004, 561:94-98.

22. Cannon RO III: Role of nitric oxide in cardiovascular disease: focus on the endothelium. Clin Chem 1998, 44:1809-1819.

23. Aggarwal NT, Pfister SL, Campbell WB: Hypercholesterolemia enhances 15lipoxygenase-mediated vasorelaxation and acetylcholine-induced hypotension. Arterioscler Thromb Vasc Biol 2008, 28:2209-2215.

24. Avis HJ, Vissers MN, Stein EA, Wijburg FA, Trip MD, Kastelein JJ, Hutten BA: A systematic review and meta-analysis of statin therapy in children with familial hypercholesterolemia. Arterioscler Thromb Vasc Biol 2007, 27:1803-1810.

25. Stancu C, Sima A: Statins: mechanism of action and effects. I Cell Mol Med 2001, 5:378-387.

26. Dilaveris P, Giannopoulos G, Riga M, Synetos A, Stefanadis C: Beneficial effects of statins on endothelial dysfunction and vascular stiffness. Curr Vasc Pharmacol 2007, 5:227-237.

27. Baigent C, Keech A, Kearney PM, Blackwell L, Buck G, Pollicino C, Kirby A, Sourjina T, Peto R, Collins R, et al: Efficacy and safety of cholesterollowering treatment: prospective meta-analysis of data from 90,056 participants in 14 randomised trials of statins. Lancet 2005, 366:1267-1278.

28. Leigh SE, Foster AH, Whittall RA, Hubbart CS, Humphries SE: Update and analysis of the University College London low density lipoprotein receptor familial hypercholesterolemia database. Ann Hum Genet 2008, 72:485-498.

29. Goldstein JL, Hobbs HH, Brown MS: Familial hypercholesterolemia. In The metabolic and molecular bases of inherited diseases. Edited by: Scriver CR, Beaudet AL, Sly WS. New York: McGraw-Hill Book Co; 2001:2863-2913.

30. McNeely MJ, Edwards KL, Marcovina SM, Brunzell JD, Motulsky AG, Austin MA: Lipoprotein and apolipoprotein abnormalities in familial combined hyperlipidemia: a 20-year prospective study. Atherosclerosis 2001, 159:471-481.

31. Goligorsky MS: Endothelial cell dysfunction: can't live with it, how to live without it. Am J Physiol Renal Physiol 2005, 288:F871-F880.

32. Ogita H, Liao J: Endothelial function and oxidative stress. Endothelium 2004, 11:123-132.

33. Woodman $C R$, Ingram D, Bonagura J, Laughlin MH: Exercise training improves femoral artery blood flow responses to endotheliumdependent dilators in hypercholesterolemic pigs. Am J Physiol Heart Circ Physiol 2006, 290:H2362-H2368.

34. Stokes KY, Russell JM, Jennings MH, Alexander JS, Granger DN: Plateletassociated $\mathrm{NAD}(\mathrm{P}) \mathrm{H}$ oxidase contributes to the thrombogenic phenotype induced by hypercholesterolemia. Free Radic Biol Med 2007, 43:22-30.

35. Sorensen KE, Celermajer DS, Georgakopoulos D, Hatcher G, Betteridge DJ, Deanfield JE: Impairment of endothelium-dependent dilation is an early event in children with familial hypercholesterolemia and is related to the lipoprotein(a) level. J Clin Invest 1994, 93:50-55. 
36. Mietus-Snyder M, Malloy MJ: Endothelial dysfunction occurs in children with two genetic hyperlipidemias: improvement with antioxidant vitamin therapy. J Pediatr 1998, 133:35-40.

37. Henderson KK, Turk JR, Rush JW, Laughlin MH: Endothelial function in coronary arterioles from pigs with early-stage coronary disease induced by high-fat, high-cholesterol diet: effect of exercise. J Appl Physiol 2004, 97:1159-1168.

38. Ingram DG, Newcomer SC, Price EM, Eklund KE, McAllister RM, Laughlin MH: Chronic nitric oxide synthase inhibition blunts endothelium-dependent function of conduit coronary arteries, not arterioles. Am J Physiol Heart Circ Physiol 2007, 292:H2798-H2808.

39. Green DJ, Walsh JH, Maiorana A, Burke V, Taylor RR, O'Driscoll JG: Comparison of resistance and conduit vessel nitric oxide-mediated vascular function in vivo: effects of exercise training. J Appl Physiol 2004, 97:749-755.

40. Walsh JH, Yong G, Cheetham C, Watts GF, O'Driscoll GJ, Taylor RR, Green DJ: Effects of exercise training on conduit and resistance vessel function in treated and untreated hypercholesterolaemic subjects. Eur Heart J 2003, 24:1681-1689.

41. Aggarwal NT, Pfister SL, Gauthier KM, Chawengsub Y, Baker JE, Campbell WB: Chronic hypoxia enhances 15-lipoxygenase-mediated vasorelaxation in rabbit arteries. Am J Physiol Heart Circ Physiol 2009, 296 H678-H688.

42. Wassmann S, Nickenig G: Interrelationship of free oxygen radicals and endothelial dysfunction-modulation by statins. Endothelium 2003, 10:23-33.

43. Pfister SL, Spitzbarth N, Edgemond W, Campbell WB: Vasorelaxation by an endothelium-derived metabolite of arachidonic acid. Am J Physiol 1996, 270:H1021-H1030

44. Pfister SL: Characterization of endothelial thromboxane receptors in rabbit aorta. Prostaglandins Other Lipid Mediat 2008, 87:54-61.

45. Pfister SL: Aortic thromboxane receptor deficiency alters vascular reactivity in cholesterol-fed rabbits. Atherosclerosis 2006, 189:358-363.

46. Kobayashi T, Tahara Y, Matsumoto M, Iguchi M, Sano H, Murayama T, Arai H, Oida H, Yurugi-Kobayashi T, Yamashita JK, et al: Roles of thromboxane $\mathrm{A}(2)$ and prostacyclin in the development of atherosclerosis in apoE-deficient mice. J Clin Invest 2004, 114:784-794.

47. Keulen ET, Schaper NC, Houben AJ, van Lin JM, Lutgens I, Rijkers K, lingaThie GM, de Bruin TW: Reduced structural and functional skin capillaries in familial combined hyperlipidemia affected men, associated with increased remnant-like lipoprotein cholesterol levels. Atherosclerosis 2002, 163:355-362.

48. Pitkanen OP, Raitakari OT, Niinikoski H, Nuutila P, lida H, Voipio-Pulkki LM, Harkonen R, Wegelius U, Ronnemaa T, Viikari J, et al: Coronary flow reserve is impaired in young men with familial hypercholesterolemia. J Am Coll Cardiol 1996, 28:1705-1711.

49. Kaufmann PA, Gnecchi-Ruscone T, Schafers KP, Luscher TF, Camici PG: Low density lipoprotein cholesterol and coronary microvascular dysfunction in hypercholesterolemia. J Am Coll Cardiol 2000, 36:103-109.

50. Kasiske BL, O'Donnell MP, Cleary MP, Keane WF: Treatment of hyperlipidemia reduces glomerular injury in obese Zucker rats. Kidney Int 1988, 33:667-672.

51. Villanova N, Moscatiello S, Ramilli S, Bugianesi E, Magalotti D, Vanni E, Zoli M, Marchesini G: Endothelial dysfunction and cardiovascular risk profile in nonalcoholic fatty liver disease. Hepatology 2005, 42:473-480.

52. Scalia R, Appel JZ III, Lefer AM: Leukocyte-endothelium interaction during the early stages of hypercholesterolemia in the rabbit: role of P-selectin, ICAM-1, and VCAM-1. Arterioscler Thromb Vasc Biol 1998, 18:1093-1100.

53. Stokes KY, Calahan L, Hamric CM, Russell JM, Granger DN: CD40/CD40L contributes to hypercholesterolemia-induced microvascular inflammation. Am J Physiol Heart Circ Physiol 2009, 296:H689-H697.

54. Pasceri V, Cheng JS, Willerson JT, Yeh ET: Modulation of C-reactive protein-mediated monocyte chemoattractant protein-1 induction in human endothelial cells by anti-atherosclerosis drugs. Circulation 2001, 103:2531-2534.

55. Nelken NA, Coughlin SR, Gordon D, Wilcox JN: Monocyte chemoattractant protein-1 in human atheromatous plaques. J Clin Invest 1991, 88:1121-1127.

56. Stapleton PA, Goodwill AG, James ME, D'Audiffret AC, Frisbee JC: Differential Impact of Familial Hypercholesterolemia and Combined
Hyperlipidemia on Vascular Wall and Network Remodeling in Mice. Microcirculation 2010, 17:47-58.

57. Simionescu M: Implications of early structural-functional changes in the endothelium for vascular disease. Arterioscler Thromb Vasc Biol 2007, 27:266-274.

58. Sudano I, Spieker LE, Hermann F, Flammer A, Corti R, Noll G, Luscher TF: Protection of endothelial function: targets for nutritional and pharmacological interventions. J Cardiovasc Pharmacol 2006, 47(Suppl 2): S136-S150.

59. Hashimoto H, Kitagawa K, Hougaku H, Shimizu Y, Sakaguchi M, Nagai Y, lyama S, Yamanishi H, Matsumoto M, Hori M: C-reactive protein is an independent predictor of the rate of increase in early carotid atherosclerosis. Circulation 2001, 104:63-67.

60. Calabro P, Yeh ET: The pleiotropic effects of statins. Curr Opin Cardiol 2005, 20:541-546.

61. Harrison DG: Endothelial function and oxidant stress. Clin Cardiol 1997, 20 II-7.

62. Cave A: Selective targeting of NADPH oxidase for cardiovascular protection. Curr Opin Pharmacol 2009, 9:208-213.

63. Schulz E, Munzel T: NOX5, a new "radical" player in human atherosclerosis? J Am Coll Cardiol 2008, 52:1810-1812.

64. Forstermann $U$, Munzel $\mathrm{T}$ : Endothelial nitric oxide synthase in vascular disease: from marvel to menace. Circulation 2006, 113:1708-1714.

65. Faraci FM, Didion SP: Vascular protection: superoxide dismutase isoforms in the vessel wall. Arterioscler Thromb Vasc Biol 2004, 24:1367-1373.

66. Guo Z, Ran Q, Roberts LJ, Zhou L, Richardson A, Sharan C, Wu D, Yang H: Suppression of atherogenesis by overexpression of glutathione peroxidase-4 in apolipoprotein E-deficient mice. Free Radic Biol Med 2008, 44:343-352.

67. Cai H, Harrison DG: Endothelial dysfunction in cardiovascular diseases: the role of oxidant stress. Circ Res 2000, 87:840-844.

68. Berliner JA, Watson AD: A role for oxidized phospholipids in atherosclerosis. N Engl J Med 2005, 353:9-11.

69. Mugge A, Elwell JH, Peterson TE, Hofmeyer TG, Heistad DD, Harrison DG: Chronic treatment with polyethylene-glycolated superoxide dismutase partially restores endothelium-dependent vascular relaxations in cholesterol-fed rabbits. Circ Res 1991, 69:1293-1300.

70. Sakurai K, Sawamura T: Stress and vascular responses: endothelial dysfunction via lectin-like oxidized low-density lipoprotein receptor-1: close relationships with oxidative stress. J Pharmacol Sci 2003, 91:182-186.

71. Tsimikas S, Brilakis ES, Miller ER, McConnell JP, Lennon RJ, Kornman KS, Witztum JL, Berger PB: Oxidized phospholipids, Lp(a) lipoprotein, and coronary artery disease. N Engl J Med 2005, 353:46-57.

72. Kinlay S: Low-density lipoprotein-dependent and -independent effects of cholesterol-lowering therapies on C-reactive protein: a meta-analysis. $J$ Am Coll Cardiol 2007, 49:2003-2009.

73. Liu PY, Liu YW, Lin LJ, Chen JH, Liao JK: Evidence for statin pleiotropy in humans: differential effects of statins and ezetimibe on rho-associated coiled-coil containing protein kinase activity, endothelial function, and inflammation. Circulation 2009, 119:131-138.

74. Maki-Petaja KM, Booth AD, Hall FC, Wallace SM, Brown J, McEniery CM, Wilkinson IB: Ezetimibe and simvastatin reduce inflammation, disease activity, and aortic stiffness and improve endothelial function in rheumatoid arthritis. J Am Coll Cardiol 2007, 50:852-858.

75. Pearson TA, Ballantyne CM, Veltri E, Shah A, Bird S, Lin J, Rosenberg E, Tershakovec AM: Pooled analyses of effects on C-reactive protein and low density lipoprotein cholesterol in placebo-controlled trials of ezetimibe monotherapy or ezetimibe added to baseline statin therapy. Am J Cardiol 2009, 103:369-374

76. Jasinska M, Owczarek J, Orszulak-Michalak D: Statins: a new insight into their mechanisms of action and consequent pleiotropic effects. Pharmacol Rep 2007, 59:483-499.

77. Vlachopoulos C, Aznaouridis K, Dagre A, Vasiliadou C, Masoura C, Stefanadi E, Skoumas J, Pitsavos C, Stefanadis C: Protective effect of atorvastatin on acute systemic inflammation-induced endothelial dysfunction in hypercholesterolaemic subjects. Eur Heart J 2007, 28:2102-2109.

78. Grodzinska L, Starzyk D, Bieron K, Goszcz A, Korbut R: Simvastatin effects in normo- and hypercholesterolaemic patients with peripheral arterial occlusive disease: a pilot study. Basic Clin Pharmacol Toxicol 2005, 96:413-419. 
79. Laufs U: Beyond lipid-lowering: effects of statins on endothelial nitric oxide. Eur J Clin Pharmacol 2003, 58:719-731

80. Miura S, Saku K: Ezetimibe, a selective inhibitor of the transport of cholesterol. Intern Med 2008, 47:1165-1170.

81. Robinson JG, Davidson MH: Combination therapy with ezetimibe and simvastatin to achieve aggressive LDL reduction. Expert Rev Cardiovasc Ther 2006, 4:461-476.

82. Cole P, Rabasseda X: Enhanced hypercholesterolemia therapy: the ezetimibe/simvastatin tablet. Drugs Today (Barc) 2005, 41:317-327.

83. Sirvent $P$, Mercier J, Lacampagne A: New insights into mechanisms of statin-associated myotoxicity. Curr Opin Pharmacol 2008, 8:333-338.

84. Takemoto M, Liao JK: Pleiotropic effects of 3-hydroxy-3-methylglutaryl coenzyme a reductase inhibitors. Arterioscler Thromb Vasc Biol 2001, 21:1712-1719.

85. Kalinowski L, Dobrucki LW, Brovkovych V, Malinski T: Increased nitric oxide bioavailability in endothelial cells contributes to the pleiotropic effect of cerivastatin. Circulation 2002, 105:933-938.

86. Hoffman R, Brook GJ, Aviram M: Hypolipidemic drugs reduce lipoprotein susceptibility to undergo lipid peroxidation: in vitro and ex vivo studies. Atherosclerosis 1992, 93:105-113.

87. Wagner AH, Kohler T, Ruckschloss U, Just I, Hecker M: Improvement of nitric oxide-dependent vasodilatation by HMG-CoA reductase inhibitors through attenuation of endothelial superoxide anion formation. Arterioscler Thromb Vasc Biol 2000, 20:61-69.

88. Hussein O, Minasian L, Itzkovich Y, Shestatski K, Solomon L, Zidan J. Ezetimibe's effect on platelet aggregation and LDL tendency to peroxidation in hypercholesterolaemia as monotherapy or in addition to simvastatin. Br J Clin Pharmacol 2008, 65:637-645.

89. Tuzcu EM, Nicholls SJ: Statins targeting inflammation by lowering lowdensity lipoprotein? J Am Coll Cardiol 2007, 49:2010-2012.

90. Yusuf S, Lonn E, Bosch J: Lipid lowering for primary prevention. Lancet 2009, 373:1152-1155.

91. Ridker PM, Rifai N, Pfeffer MA, Sacks F, Braunwald E: Long-term effects of pravastatin on plasma concentration of $C$-reactive protein. The Cholesterol and Recurrent Events (CARE) Investigators. Circulation 1999, 100:230-235.

92. Lahera V, Goicoechea M, de Vinuesa SG, Miana M, de las HN, Cachofeiro V, Luno J: Endothelial dysfunction, oxidative stress and inflammation in atherosclerosis: beneficial effects of statins. Curr Med Chem 2007, 14:243-248.

93. Bustos C, Hernandez-Presa MA, Ortego M, Tunon J, Ortega L, Perez F, Diaz C, Hernandez G, Egido J: HMG-CoA reductase inhibition by atorvastatin reduces neointimal inflammation in a rabbit model of atherosclerosis. J Am Coll Cardiol 1998, 32:2057-2064.

94. Chung HK, Lee IK, Kang H, Suh JM, Kim H, Park KC, Kim DW, Kim YK, Ro HK, Shong M: Statin inhibits interferon-gamma-induced expression of intercellular adhesion molecule-1 (ICAM-1) in vascular endothelial and smooth muscle cells. Exp Mol Med 2002, 34:451-461.

95. Stefanick ML, Mackey S, Sheehan M, Ellsworth N, Haskell WL, Wood PD: Effects of diet and exercise in men and postmenopausal women with low levels of HDL cholesterol and high levels of LDL cholesterol. $N$ Engl J Med 1998, 339:12-20.

96. Haskell WL, Lee IM, Pate RR, Powell KE, Blair SN, Franklin BA, Macera CA, Heath GW, Thompson PD, Bauman A: Physical activity and public health: updated recommendation for adults from the American College of Sports Medicine and the American Heart Association. Med Sci Sports Exerc 2007, 39:1423-1434.

97. Kingwell BA: Nitric oxide-mediated metabolic regulation during exercise: effects of training in health and cardiovascular disease. FASEB J 2000 14:1685-1696.

98. Maxwell AJ, Schauble E, Bernstein D, Cooke JP: Limb blood flow during exercise is dependent on nitric oxide. Circulation 1998, 98:369-374.

99. Durstine JL, Grandjean PW, Davis PG, Ferguson MA, Alderson NL, DuBose KD: Blood lipid and lipoprotein adaptations to exercise: a quantitative analysis. Sports Med 2001, 31:1033-1062.

100. Goto C, Nishioka K, Umemura T, Jitsuiki D, Sakagutchi A, Kawamura M, Chayama K, Yoshizumi M, Higashi Y: Acute moderate-intensity exercise induces vasodilation through an increase in nitric oxide bioavailiability in humans. Am J Hypertens 2007, 20:825-830.
101. de Moraes C, Davel AP, Rossoni LV, Antunes E, Zanesco A: Exercise training improves relaxation response and SOD-1 expression in aortic and mesenteric rings from high caloric diet-fed rats. BMC Physiol 2008, 8:12.

102. Bai Y, Sigala W, Adams GR, Vaziri ND: Effect of exercise on cardiac tissue oxidative and inflammatory mediators in chronic kidney disease. Am J Nephrol 2009, 29:213-221.

103. Peake J, Nosaka K, Suzuki K: Characterization of inflammatory responses to eccentric exercise in humans. Exerc Immunol Rev 2005, 11:64-85.

104. Pedersen BK, Febbraio MA: Muscle as an endocrine organ: focus on muscle-derived interleukin-6. Physiol Rev 2008, 88:1379-1406.

105. Pedersen BK: The diseasome of physical inactivity-and the role of myokines in muscle-fat cross talk. J Physiol 2009, 587:5559-5568.

106. Pedersen BK, Akerstrom TC, Nielsen AR, Fischer CP: Role of myokines in exercise and metabolism. J Appl Physiol 2007, 103:1093-1098.

107. Pedersen BK, Fischer CP: Physiological roles of muscle-derived interleukin6 in response to exercise. Curr Opin Clin Nutr Metab Care 2007, 10:265-271.

108. Pedersen BK, Hoffman-Goetz L: Exercise and the immune system: regulation, integration, and adaptation. Physiol Rev 2000, 80:1055-1081

109. Reese EP: Arthritis; the use of physical therapy as an aspect of management. Calif Med 1958, 89:204-209.

110. Oberbach A, Lehmann S, Kirsch K, Krist J, Sonnabend M, Linke A, Tonjes A, Stumvoll $M$, Bluher $M$, Kovacs $P$ : Long-term exercise training decreases interleukin-6 (IL-6) serum levels in subjects with impaired glucose tolerance: effect of the $-174 \mathrm{G} / \mathrm{C}$ variant in IL-6 gene. Eur J Endocrinol 2008, 159:129-136.

111. Lemos ET, Reis F, Baptista S, Pinto R, Sepodes B, Vala H, Rocha-Pereira P, Silva GC, Teixeira N, Silva AS, et al: Exercise training decreases proinflammatory profile in Zucker diabetic (type 2) fatty rats. Nutrition 2008, 25:330-9.

112. Wilund KR: Is the anti-inflammatory effect of regular exercise responsible for reduced cardiovascular disease? Clin Sci (Lond) 2007, 112:543-555

113. Rich PR: The molecular machinery of Keilin's respiratory chain. Biochem Soc Trans 2003, 31:1095-1105.

114. Bloomer RJ: Effect of exercise on oxidative stress biomarkers. Adv Clin Chem 2008, 46:1-50.

115. Ji LL: Antioxidants and oxidative stress in exercise. Proc Soc Exp Biol Med 1999, 222:283-292

116. Brennan ML, Penn MS, Van LF, Nambi V, Shishehbor MH, Aviles RJ, Goormastic M, Pepoy ML, McErlean ES, Topol EJ, et al: Prognostic value of myeloperoxidase in patients with chest pain. N Engl J Med 2003, 349:1595-1604.

117. Meilhac O, Ramachandran S, Chiang K, Santanam N, Parthasarathy S: Role of arterial wall antioxidant defense in beneficial effects of exercise on atherosclerosis in mice. Arterioscler Thromb Vasc Biol 2001, 21:1681-1688.

118. Mignini F, Tomassoni $D$, Traini $E$, Streccioni V: Antioxidant endogenous defense in a human model of physical stress. Clin Exp Hypertens 2008, 30:776-784.

119. Seals DR, Desouza CA, Donato AJ, Tanaka H: Habitual exercise and arterial aging. J Appl Physiol 2008, 105:1323-1332.

120. Fukai T, Siegfried MR, Ushio-Fukai M, Cheng Y, Kojda G, Harrison DG: Regulation of the vascular extracellular superoxide dismutase by nitric oxide and exercise training. J Clin Invest 2000, 105:1631-1639.

121. Sun MW, Zhong MF, Gu J, Qian FL, Gu JZ, Chen H: Effects of different levels of exercise volume on endothelium-dependent vasodilation: roles of nitric oxide synthase and heme oxygenase. Hypertens Res 2008, 31:805-816.

122. de Winther MP, Kanters E, Kraal G, Hofker MH: Nuclear factor kappaB signaling in atherogenesis. Arterioscler Thromb Vasc Biol 2005, 25:904-914.

doi:10.1186/1476-9255-7-54

Cite this article as: Stapleton et al:: Hypercholesterolemia and microvascular dysfunction: interventional strategies. Journal of Inflammation 2010 7:54. 